\title{
O estudo do meio na educação ambiental formal: contribuições da ciência geográfica
}

Luna Letícia de Mattos Lambert Maria Lídia Bueno Fernandes Universidade de Brasília (UnB)

Este artigo avalia a relação entre a geografia e a educação ambiental críticas. Toma o estudo do meio como metodologia de ensino que pode promover essa aproximação. Ancora-se na teoria geográfica de Santos, em Leff, Layrargues e Loureiro na educação ambiental, em Fernandes, Lopes e Pontuschka na abordagem sobre estudo do meio. Trata-se de pesquisa mista. Projetos de educação ambiental de escolas públicas do Distrito Federal apresentados na etapa distrital da IV Conferência Nacional Infantojuvenil pelo Meio Ambiente (IV CNIJMA), em 2013, são o referencial empírico. Avalia-se a relação entre as propostas teóricas e os projetos das escolas. Identificou-se que o estudo do meio é capaz de relacionar essas áreas com foco na transformação social, mas não é utilizado nas escolas.

Palavras-chave: Transformação social. Espacialidade. Construtivismo. 


\section{Field work for environmental education: geographic theory contributions}

The article discusses the relationship between geography and environmental education criticism. Takes field work as a pedagogical method that can promote this approach. Is anchored on the geographical theory of Santos, in Leff, Layrargues and Loureiro in environmental education and Fernandes and Lopes and Pontuschka in field work. This is a joint research and environmental education projects of Federal District's public schools presented at the IV CNIJMA in 2013 are the empirical reference. It analyzes the relationship between environmental education theoretical proposals and projects of schools. It was identified that field work is a good alternative to relate these areas with a focus on social transformation, but is not used in schools.

Keywords: Social change. Spatiality. Constructivism.

\section{El estudio del entorno en la educación ambiental formal: contribuciones de la ciencia geográfica}

El artículo analiza la relación entre la geografía y la educación ambiental crítica. Toma estudio del entorno como un enfoque pedagógico que puede promover este aproximación. Está anclado en la teoria geográfica de Santos, en Leff, Layrargues y Loureiro en la educación ambiental y en Fernandes, Lopes y Pontuschka en el estudio del entorno. Se trata de una investigación mista y proyectos de educación ambiental en las escuelas públicas del Distrito Federal, que se han presentado en la IV CNIJMA en 2013, son la referencia empírica. Se analiza la relación entre las propuestas teóricas de la educación ambiental y los proyectos de las escuelas. Se identificó que lo estudio del entorno es capaz de relacionar estas áreas con un enfoque en la transformación social, pero no se utiliza en las escuelas.

Palabras clave: Cambio social. La espacialidad. Constructivismo. 


\section{Introdução}

O desenvolvimento da sociedade no âmbito do sistema capitalista, ao passo que promoveu avanços científico-tecnológicos e aprimorou a qualidade de vida da sociedade em diversas áreas, criou também um contexto de degradação dos sistemas naturais e da condição humana. Atualmente se observa a incompatibilidade entre a sobrevivência dos ecossistemas e a repartição justa de recursos vitais em um sistema social baseado na acumulação. Diversos estudos ${ }^{1}$ demonstram que a velocidade de degradação dos ecossistemas está maior que sua capacidade de restauração e que os níveis de pobreza mantêm-se apesar dos avanços tecnológicos. ${ }^{2}$ Das evidências do colapso socioambiental no qual se encontra a sociedade do século XXI, desponta a consciência sobre a necessidade de mudanças, especialmente nos princípios e valores que regem a relação da sociedade com o seu meio. Diversos atores sociais desenvolveram teorias e práticas voltadas para aprimorar a qualidade da relação do ser humano com seu espaço de vivência, visando reduzir os "efeitos colaterais" dos avanços capitalistas.

Nesse contexto surge a educação ambiental como proposta de reconstruir a relação do homem com seu meio de vivência. Entre as diferentes correntes da educação ambiental, adota-se aqui a pautada no pensamento crítico, que utiliza da teoria de Paulo Freire (1967) para defender a ideia de formação de sujeitos sociais emancipados. A pedagogia sob essa ótica entende a liberdade como sua matriz e, para tanto, deve contar com a participação livre e crítica dos educandos. Freire (2011) considera que a realidade dos educandos deve ser o ponto de partida para o desenvolvimento do aprendizado, eliminando a ideologia dominante oculta nos currículos formais e exercendo o caráter político da educação.

Inspirada nessa linha de pensamento, a prática da educação ambiental deve ser imersa na vida, na história e nas questões dos tempos atuais, contribuindo para a intervenção sobre os conflitos socioambientais a partir da compreensão crítica da relação sociedade-meio.

Considera-se que, quando ancoradas no pensamento crítico, a educação ambiental e a ciência geográfica apresentam significativas complementaridades na perspectiva do ensino escolar. Trabalha-se com a asserção de que a abordagem pedagógica do estudo do meio, uma prática de ensino desencadeada a partir da espacialidade, baseada na perspectiva construtivista da educação, potencializa o caráter de transformação social da prática de educação ambiental.

1 Segundo o Relatório de Avaliação Ecossistêmica do Milênio (2005), 15 dos 24 serviços ecossistêmicos analisados estão sendo degradados a uma velocidade maior que a sua capacidade de regeneração.

2 A Organização das Nações Unidas (ONU) aponta, no relatório Estado da Insegurança Alimentar no Mundo (2012), que aproximadamente 870 milhões de pessoas são subnutridas e 783 milhões não têm acesso à água potável. 
Adotam-se enquanto objetivos específicos: avaliar a complementaridade entre a teoria crítica da geografia e a educação ambiental a partir de revisão bibliográfica; apresentar os procedimentos e a abordagem pedagógica construtivista desenvolvidos em um estudo do meio; e, por fim, avaliar nove projetos, com o tema resíduos sólidos, apresentados na etapa distrital da IV Conferência Nacional Infantojuvenil pelo Meio Ambiente (IV CNIJMA), a fim de identificar se suas propostas apresentam os elementos contemplados por tal metodologia de ensino.

A análise empírica se dá sobre os projetos apresentados pelas escolas da rede pública de ensino do Distrito Federal na IV CNIJMA, em 2013. Abrangem o ensino fundamental ( $6^{\circ}$ a $9^{\circ}$ anos) e foram escritos conforme as orientações formais para a participação na conferência, que teve como documento norteador a publicação do Ministério da Educação (MEC) "Vamos cuidar do Brasil com escolas sustentáveis: educando-nos para pensar e agir em tempos de mudanças socioambientais globais".

Primeiramente são apresentados os elementos fundantes da proposta da educação ambiental crítica, vinculados ao método de análise da geografia crítica, que tem em Santos um grande expoente. Em seguida, o estudo do meio, ancorado nas propostas da pedagogia construtivista espanhola, é apresentado enquanto metodologia de ensino que possibilita a prática pedagógica da educação ambiental formal com a utilização do método geográfico de análise espacial. Depois, são avaliados os nove projetos sobre resíduos sólidos apresentados na etapa distrital da IV CNIJMA, em 2013. Por fim, apresentam-se as conclusões desenvolvidas ao longo da reflexão sobre a temática.

\section{Diálogos entre educação ambiental e ciência geográfica críticas}

A educação ambiental emerge de movimentos sociais organizados, especialmente durante a década de 1960, em um contexto de crise socioambiental. As consequências do modo de vida pautado no acúmulo de bens materiais e no circuito de produção e consumo desenfreado tornaram-se mais evidentes, visto que as promessas de bem-estar e melhoria dos padrões sociais advindas do desenvolvimento técnicocientífico-industrial mostravam-se claramente restritas a grupos sociais específicos e embutiam em sua lógica um alto custo ambiental.

Ancorada na lógica de repúdio ao processo de degradação da natureza, a educação ambiental assumiu um pensamento naturalista e procurou formas de proteger as áreas naturais da predação humana. Entretanto, os discursos e as práticas de educação ambiental diversificaram-se. Segundo Layrargues e Lima (2011), a educação ambiental constitui um campo do conhecimento heterogêneo, pois conta com perspectivas contraditórias que disputam hegemonia nas teorias e práticas 
desta educação.

Quando se vincula ao pensamento crítico, as questões abordadas na educação ambiental tornam-se mais abrangentes e propõem a transformação social. Adentram um embate por outro projeto societário, com questionamentos sobre os alicerces da sociedade capitalista, e ultrapassam a perspectiva meramente natural. Para assumir um discurso que abarca as questões sociais, uma vez que ambas estão profundamente imbricadas, a educação ambiental supera o discurso de harmonização com a natureza e respeito aos seres vivos, para entrar no mérito da compreensão sobre o contexto socio-histórico que levou à construção da realidade concreta, interpretando os conflitos sociais e ambientais dialeticamente. Desta forma, adentra as relações da sociedade ocidental capitalista para desvelar suas contradições e pensar maneiras de transformá-la.

Sua base educacional é a teoria libertária de Paulo Freire (1967), que considera que a prática pedagógica deve ser imersa na vida dos educandos, na história e nas questões atuais. Entende-se que o aprendizado deve ser construído pela elucidação crítica da realidade do educando, ampliando sua consciência sobre a sociedade e seu papel nela. Logo, esta prática pedagógica visa à educação para a decisão e para a responsabilidade política e social e, portanto, envolve a identificação do educando enquanto sujeito atuante e transformador da própria realidade.

Os autores que trabalham nessa linha de pensamento, como Leff (2012), Carvalho (2004) e Layrargues (2009), apontam para a necessidade de uma reforma paradigmática da sociedade, ou seja, uma mudança na própria concepção de conhecimento. Defendem que os grupos sociais, principalmente os marginalizados, possam ter seus saberes locais valorizados e reconstruir as bases do processo produtivo, sob novas e múltiplas óticas.

Em diálogo com essa perspectiva, gostaríamos de citar Leff (2012), que, ao pensar na mudança paradigmática que envolve a reconstrução da relação da sociedade com o seu meio, desenvolve o conceito de saber ambiental. Este prevê um pensamento complexo sobre a realidade e engloba valores de respeito, ética e justiça social. Pauta-se em uma racionalidade ambiental e não capitalista e, por isso, valoriza o pensamento interdisciplinar, o vínculo entre teoria e prática e a utilização dos diferentes saberes culturais.

Considera-se que o saber ambiental adequa-se às proposições de Carvalho (2004), visto que a formação do sujeito ecológico dá-se conforme uma racionalidade que requer a construção - individual e coletiva - de valores éticos e humanos e novas formas de relação com o meio. O saber ambiental, por sua vez, não se vincula apenas ao conhecimento sobre ecossistemas, pois busca justiça social, repartição justa dos recursos e supressão das "externalidades do desenvolvimento" (LEFF, 2012, p. 19). Para Leff (2012), a degradação ambiental, a marginalização social e a concentração dos custos ecológicos entre os "desprivilegiados da sociedade" (op. cit.) representam 
externalidades do próprio processo produtivo.

A perspectiva da transformação social ganha em Layrargues (2009) expressão mais contundente. Para o autor, a desigualdade constitui uma das principais causas da insustentabilidade, caracterizada pela desintegração social. Enquanto não houver igualdade política, cultural e econômica entre os sujeitos sociais, não haverá sustentabilidade, visto que, em um contexto de desigualdade, as decisões são tomadas por grupos sociais específicos e beneficiam apenas parcela da população, em detrimento dos demais.

No campo da geografia, o autor Milton Santos (2008b) considera que um importante tema para a reflexão da questão ambiental refere-se à ideologia globalizante dos grupos hegemônicos, ou seja, o padrão único das técnicas, criado para alienar o trabalho e facilitar a obtenção de matéria-prima e mão de obra barata em diversos países, tendo como finalidade o mercado global, e não os interesses locais das diversas comunidades que habitam o planeta. Por esta razão, as escolhas dos grupos hegemônicos não são condizentes com o desenvolvimento e a melhoria de vida dos mais diferentes grupos sociais. Tendo isto em vista, como atingir a sustentabilidade sem proporcionar aos grupos excluídos, ou subjugados em suas condições de existência, a capacidade de romper com os ditames externos e hegemônicos, criando formas autônomas de produzir e se desenvolver?

Layrargues (2009) defende que a educação ambiental tem o compromisso social de combater a desigualdade e está submetida a uma dupla função: "a clássica função moral de socialização humana com a natureza, e também a pouco compreendida função ideológica de reprodução das condições sociais" (op. cit., p. 11). Explica que a dificuldade para perceber o vínculo entre a questão ambiental e a social decorre do entendimento equivocado sobre o adjetivo "ambiental", já que este foi predominantemente compreendido enquanto sinônimo de natureza.

A educação ambiental crítica vai além do aprendizado sobre o funcionamento dos sistemas naturais. É fundamental que ela elucide a estrutura dos sistemas sociais, visto que é na relação entre a sociedade e a natureza que surgem os conflitos de ordem ambiental. Neste sentido, natureza e sociedade constituem um conjunto indissociável. Layrargues (2009) sugere que, ao invés de se falar em problema ambiental, deve-se tratar de conflitos socioambientais, para trazer a disputa social para o centro da análise. Para o autor, a educação ambiental:

é aquela que articula a discussão da relação entre o ser humano e a natureza inserida no contexto das relações sociais. É aquela que propicia o desenvolvimento de uma consciência ecológica no educando, mas que contextualiza seu projeto político-pedagógico de modo a enfrentar também a padronização cultural, exclusão social, concentração de renda, apatia política, além da degradação da natureza. É aquela que enfrenta o desafio da complexidade, incorporando na reflexão categorias de análise, como trabalho, mercadoria e alienação. É aquela que expõe as 
contradições das sociedades assimétricas e desiguais (LAYRARGUES, 2009, p. 28).

Além de seu caráter ambiental, a educação ambiental é também uma prática pedagógica. Layrargues (2009), com isso, destaca que toda forma de educação pode ter como cunho ideológico a manutenção do status quo ou a perspectiva de transformação. Defende, então, que a educação ambiental deva assumir o compromisso de transformar as relações sociais e incorporar a questão da justiça distributiva e das externalidades do desenvolvimento.

Os conflitos distributivos decorrem da desigualdade de direito de uso dos elementos naturais. Leff (2012) destaca que o modo de produção dominante priva os grupos sociais dominados de suas condições ecológicas de sobrevivência. Como exemplo, podemos citar os diversos casos em que comunidades tradicionais perdem suas terras devido ao avanço da fronteira agropecuária ou, ainda, com a chegada dos grandes projetos, como no caso das usinas hidrelétricas.

A linha crítica da educação ambiental, além de entender a sustentabilidade de forma ampla, propõe que forme para a emancipação social, pois entende que com o fortalecimento dos grupos sociais locais frente às imposições da ideologia hegemônica é possível construir a sustentabilidade social, política e territorial e, como consequência, ambiental.

Tendo essa meta, a educação ambiental dá ênfase à necessidade de vincular a produção do conhecimento ao saber cotidiano dos educandos. Layrargues (2009) destaca a importância da contextualização no ato pedagógico, para que ele não produza conhecimentos reduzidos à questão de natureza apenas. Para o autor, "o contexto (político, cultural, socioeconômico) desponta como elemento estruturante para ressignificar o atributo ambiental a não ficar reduzido à sua dimensão natural" (LAYRARGUES, 2009, p. 23).

Defende que a educação ambiental deve ter caráter de emancipação social e expor as contradições da sociedade assimétrica e desigual como forma de motivar os sujeitos a lutarem em defesa de seus direitos. Neste sentido, ocorreria a politização do debate ambiental, devido à mobilização dos indivíduos enquanto sujeitos de direito participantes da vida pública.

Temos, portanto, que a educação ambiental crítica é, acima de tudo, política, e se faz enquanto luta para a transformação da sociedade. Por isso, não cabe reduzir sua prática à transformação individual. Da mesma forma, Loureiro (2006) considera que os seres humanos constituem uma unidade entre três dimensões: pedagógica, ecológica e política. Assim, as práticas de educação ambiental precisam estar relacionadas ao ato político, ou seja, à problematização da realidade individual e coletiva como estímulo à participação ativa nas decisões sociais.

Ele considera que somente na prática social a mudança opera-se objetivamente e, 
por isso, seria simplista a pretensão de mudar o indivíduo sem, primeiramente, mudar a realidade social na qual ele é sujeito. Tendo em vista que a educação ambiental fazse em uma arena de embates por um projeto de sociedade, considera-se que "é a ação de mudança individual associada à ação política que pode vincular este movimento das pessoas a transformações societárias" (LOUREIRO, 2006, p. 109).

É importante, portanto, que os sujeitos compreendam o funcionamento da sociedade no mundo e seu próprio papel enquanto sujeitos ativos na sociedade. Por isso, a partir do ponto de vista político da educação ambiental, assume-se a intenção de transformar a ação cotidiana dos indivíduos a partir da compreensão do educando enquanto sujeito de seu lugar de vivência. Isto faz com que seja relevante o estabelecimento de práticas dialógicas com o meio, propiciando a análise crítica da realidade vivida pelos educandos.

Nesse sentido, temos, em Leff (2012), que a pedagogia ambiental expressa-se no contato dos educandos com seu entorno natural e social. O autor defende que a educação ambiental ensine a partir da confrontação com a realidade e do estabelecimento de diálogo com o meio, para que se promova a apreensão das múltiplas e complexas cadeias inter-relacionais que compõem a realidade.

Propomos, então, uma aproximação entre a educação ambiental crítica e a teoria geográfica, que tem como objeto de estudo o espaço geográfico, ou seja, o meio de vivência da sociedade em nível material e simbólico. Nesta relação, a geografia apresenta fundamentos teóricos relevantes para a elucidação crítica dos elementos manifestados concretamente na vivência espacial dos educandos.

Assim, ancoramo-nos em Milton Santos, para quem o espaço geográfico é subordinado à ação da sociedade, que o molda conforme seu modo de produção, mas é também, em uma relação dialética, subordinante, visto que gera necessidades, impõe limitações e apresenta possibilidades. O espaço geográfico não é palco de ação da sociedade, pois compõe com ela a própria realidade, sendo a sociedade e o meio um conjunto indissociável. Aqui percebemos um paralelo significativo com o preceito assumido pelos educadores ambientais críticos, que consideram sociedade e natureza enquanto elementos indissociáveis, tal qual explicitado anteriormente.

Santos (2012, p. 61) assume o espaço geográfico como um "híbrido", "uno e múltiplo" resultado da inseparabilidade entre "sistemas de objetos" e "sistemas de ações". Os objetos geográficos são tudo o que existe sobre a superfície terrestre, tanto os elementos naturais quanto os humanos. As ações constituem os atos projetados para atingir algum fim; comportam, portanto, as ideologias que norteiam a ação social. No espaço estão materializadas as questões históricas e sociais e sua análise crítica nos possibilita a compreensão sobre os sistemas socioambientais.

O método de análise espacial cunhado por Santos (2008a) atende às premissas indicadas pelos teóricos da educação ambiental crítica, como a necessidade de 
apreensão das complexas cadeias relacionais a partir do pensamento sistêmico. $O$ autor sugere como ferramenta analítica da espacialidade a separação em "elementos do espaço" (op. cit., p. 15). Estes "são dotados de uma estrutura interna, pela qual participam da vida do todo de que são parte e que lhes atribui um comportamento diferente (para cada qual), como reação ao próprio jogo das forças que os atingem" (op. cit.).

O espaço é visto como um sistema abrangente que contém e é contido por outros sistemas, estando todos interligados; por isso os elementos geográficos devem ser percebidos de forma sistemática, visto que a atribuição de suas qualidades depende do contexto no qual estão inseridos. Esta relação nos evidencia um pensamento sistêmico; portanto, neste aspecto, condizente com a teoria da educação ambiental.

Para exemplificar, os elementos do espaço são as instituições, a sociedade, as firmas, o meio ecológico e as infraestruturas. Como regras fundamentais de método o autor levanta que estes são intercambiáveis, redutíveis uns aos outros e dependem das especificidades do lugar no qual se encontram. Quer dizer que existe segregação de elementos; no entanto, esta segregação envolve um pensamento complexo, visto que cada realidade, em cada lugar, é específica e os elementos assumem características próprias conforme as inter-relações que estabelecem com os outros elementos. Com isto, destacamos mais um ponto de coerência com as propostas da educação ambiental.

Santos (2008a) aponta, ainda, que os elementos do espaço estão ligados entre si por uma organização que pode funcionar em diferentes escalas, como também pode ser puramente local. Em especial na era globalizada, esta organização é definida como um conjunto de normas que regem as relações das variáveis com as demais, dentro e fora de uma área. Ou seja, os elementos de um lugar relacionam-se entre eles e entre os elementos do conjunto de lugares conforme normas próprias, locais, ao mesmo tempo em que são submetidos às normas globais.

Hoje em dia, no entanto, há uma centralização das normas sobre centros de decisão distantes e estranhos às necessidades locais. Isto faz com que as variáveis tornemse rígidas, conforme os interesses globalizados e globalizantes, e não mais sirvam para atender às necessidades locais. Para o autor, essa é uma das principais causas de desordem nos diversos locais do globo: o funcionamento conforme os padrões produtivos globais, que reduz o papel regulador das funções locais pela própria sociedade que ali vive.

Esse processo descrito por Santos enquadra-se nos alertas apresentados por teóricos da educação ambiental crítica. Para estes, o cerne dos problemas ambientais vivenciados na atualidade advém da ideologia hegemônica de produção. Englobam as questões ambientais, vinculadas à perda de biodiversidade e à contaminação de ecossistemas, mas também estão igualmente relacionados à injustiça social. 
A análise da realidade do ponto de vista geográfico apresenta contribuições para a educação ambiental. A prática dos aprendizes é socioespacial; eles criam e recriam espacialidades todo o tempo. A leitura crítica sobre essa realidade pode contribuir para a formação do pensamento autônomo, a partir do desvelamento das contradições sociais e, com isso, motivar a atribuição de novos valores aos elementos do espaço.

Como apontado anteriormente, se há intenção em se estabelecer processos pedagógicos que coloquem o educando em diálogo com o meio, refletindo sobre seu cotidiano e as relações que se fazem entre os elementos que vivencia diretamente, como escola, empresas locais, organizações sociais, órgãos públicos, igrejas e outros vinculados às estruturas físicas, como as áreas naturais e humanizadas, a apropriação do conhecimento geográfico faz-se pertinente.

Para que os grupos sociais estabeleçam formas próprias de agir e de produzir seu espaço, primeiramente devem compreendê-lo em sua amplitude. A ênfase sobre o agir local torna-se muito relevante no sentido que reverte a ordem ideológica de dominação, na qual as ordens provindas dos centros de decisão começam a enfraquecer conforme as sociedades locais conscientizam-se dos processos aos quais estão subjugadas, compreendem as necessidades locais e podem, conscientemente, adotar as atitudes necessárias para supri-las e transformá-las (SANTOS, 2012).

\section{A metodologia de ensino estudo do meio}

Identificou-se na metodologia de ensino estudo do meio, ancorada na pedagogia construtivista e no método dialético, a potencialidade de não somente desencadear a aprendizagem a partir da espacialidade, como também de estimular o desenvolvimento de atitudes e comportamentos compatíveis com os propósitos da educação ambiental.

Antes de adentrar na definição de estudo do meio, contudo, faz-se necessário explanar sobre a abordagem construtivista da educação. Os referenciais teóricos dessa perspectiva reconhecem o protagonismo dos sujeitos do ensino e da aprendizagem, assim como as questões sociais e culturais aos quais ambos necessariamente estão inseridos. Considera-se, portanto, que o processo educativo está vinculado a uma dupla dimensão: a social e a individual. Para integrar essas duas, os autores falam na importância de se considerar, entre outros aspectos, os conteúdos de aprendizagem como produtos sociais.

Os conteúdos de aprendizagem são divididos em três por Zabala (2009, p. 161): aquilo que os alunos devem saber, chamados de conteúdos conceituais; o que eles devem saber fazer, que são os conteúdos procedimentais; e o que eles devem ser, 
chamados de conteúdos atitudinais.

A metodologia de ensino estudo do meio, sob essa perspectiva, assume diversas estratégias de confrontação com a realidade para que o educando possa construir seu conhecimento a partir do desvelamento crítico da realidade. Lopes e Pontuschka (2009) definem esta metodologia como uma ferramenta metodológica interdisciplinar "que visa proporcionar para alunos e professores o contato direto com determinada realidade [...]. Esta atividade pedagógica se concretiza pela imersão orientada na complexidade de um determinado espaço geográfico" (LOPES; PONTUSCHKA, 2009, p. 173).

Fernandes (2012) salienta que um estudo do meio conduz os estudantes a olhar o espaço como um objeto investigativo por intermédio do trabalho de campo. A condução da investigação é que desponta enquanto diferencial, porque em um estudo do meio os estudantes são levados a utilizar procedimentos científicos para desvendar a realidade que observam.

Nas palavras da autora:

um estudo do meio não é uma mera visita para se observar o que já se sabe, mas prevê um trabalho de investigação apurado, cuidadoso, com muitas leituras prévias, com levantamento de questões e preparação para uma atitude investigativa durante toda a atividade (FERNANDES, 2012, p. 59).

Fernandes (2012, p. 58) considera que "a importância de um estudo do meio, para além da formação de um espírito científico, deve-se à perspectiva da transposição de um conteúdo estático e cristalizado para a vida". Ao dialogarem com o espaço, podem perceber que nele se encontram intervenções sociais, políticas, econômicas, culturais e naturais de diferentes momentos históricos.

Nesse processo é possível que os aprendizes relacionem-se com os diferentes elementos do espaço, como apresentados anteriormente. Estes se apresentam para eles enquanto reais. Suas próprias vidas podem passar a ser objeto de sua reflexão e o aprendizado sobre como se investigar em seus próprios mundos pode os levar a assumir uma postura social mais reflexiva, crítica e propositiva.

Fernandes (2012) entende que um estudo do meio é significativamente importante para a construção de uma sociedade democrática, por potencializar a capacidade de observação, interação, interpretação e a habilidade em relacioná-las entre si e com o contexto do estudante. A autora enfatiza que essa metodologia possibilita que o estudante construa sua própria aprendizagem a partir de sua leitura de mundo.

A transformação individual decorrente da aprendizagem crítica sobre a realidade não pode, contudo, ser desencadeada apenas com o desenvolvimento de conteúdos conceituais, visto que envolve valores e atitudes. Para que o sujeito transforme sua ação e, consequentemente, possa transformar seu espaço, os processos educativos 
devem contemplar o processo da ação e da produção do conhecimento. E é neste outro aspecto que o estudo do meio torna-se ainda mais relevante. Este engloba recursos que viabilizam o desenvolvimento dos três conteúdos de aprendizagem, os conceituais, os atitudinais e os procedimentais de forma equilibrada. Além disso, assume um enfoque que propicia a organização dos conteúdos por disciplinas, mas engloba o entrelaçamento entre estas (FERNANDES, 2012). Desta forma, pode assumir uma abordagem interdisciplinar e elucidar sobre os conflitos socioambientais apontados por Layrargues (2009) sem dissociar sociedade e natureza.

Com essas colocações sobre tal metodologia, identifica-se um entrelaçamento significativo com a educação ambiental. Pontuam-se, a seguir, os principais elementos visados pela educação ambiental que podem ser obtidos com a prática de um estudo do meio: a) percepção crítica da realidade a partir da espacialidade; b) enfoque interdisciplinar; c) transformação de valores e atitudes individuais, com repercussão social.

A educação ambiental acredita que essa dupla dimensão, a social e a individual, deve ser construída a partir de uma relação dialógica com o meio. Isto, desde que pautado em um pensamento crítico e abrangente, pode elucidar a complexidade da realidade socioambiental e motivar a mudança de atitude individual, o que se alinha significativamente ao fato de que um estudo do meio, mais que passar conteúdos, adota uma metodologia que possibilita o desenvolvimento de habilidades investigativas, trabalhando diretamente no aprendizado de atitudes e comportamentos.

Entretanto, salienta-se também a proximidade e a relevância que o conhecimento geográfico apresenta nessa relação. A geografia pressupõe que os estudantes analisem a espacialidade e compreendam as contradições da relação sociedadenatureza, desenvolvendo um olhar crítico e o entendimento de si enquanto sujeito ativo e transformador do espaço.

Toda sociedade é espacializada e, por essa razão, qualquer ação pedagógica que vise atuar na relação da sociedade com o seu meio de vivência encontra suporte teórico na ciência geográfica. No entanto, entende-se que, diante da complexidade da realidade, a interdisciplinaridade deve ser a premissa que rege o trabalho pedagógico. A abordagem geográfica dá-se no âmbito da leitura crítica sobre os sistemas sociais materializados na realidade concreta.

Além dos elementos visados pela educação ambiental já apresentados e que podem ser potencializados pela metodologia de ensino estudo do meio, esta metodologia, se aplicada em um contexto de educação ambiental formal, também possibilita aos professores e à escola a participação na construção do currículo. Ela evidencia elementos úteis a serem incorporados no dia a dia escolar, revelando conteúdos que tenham vínculo direto com a realidade na qual a escola encontra-se inserida, como 
apontam Lopes e Pontuschka (2009).

Acredita-se, em consonância com os autores acima referenciados, que, a partir desse levantamento, a escola se fortalece para questionar eventuais situações socioambientais que se colocam para aquela comunidade escolar específica e, assim, amplia suas possibilidades de desenvolver projetos de educação ambiental que envolvam a comunidade escolar em uma abordagem interdisciplinar e crítica.

Além disso, a prática do estudo do meio pode fortalecer o vínculo com o local da escola, e a abordagem pedagógica, a partir dos elementos do espaço, auxilia a elucidação sobre as especificidades locais em relação aos ditames globais. O estudo sistematizado sobre a espacialidade local pode contribuir significativamente para que a escola construa seu currículo voltado às necessidades e aos interesses da comunidade local.

No ano de 2013 foi realizada uma Conferência de Meio Ambiente para jovens estudantes do ensino fundamental II, ou seja, $6^{\circ}$ ao $9^{\circ}$ ano. Esta ocorreu em algumas etapas, tendo sido desencadeada por processos dentro das escolas, nos quais professores e alunos foram convidados a pensar os problemas das comunidades e a elaborar projetos que visassem solucioná-los. Em seguida, estes estudantes foram para as etapas estaduais e distrital. Por fim, os melhores projetos foram apresentados na etapa nacional, chamada IV CNIJMA.

Uma das pesquisadoras deste trabalho participou como docente na etapa distrital e identificou entrelaçamentos significativos entre a proposta das conferências e as relações da geografia com a educação ambiental críticas, traduzidas na metodologia de ensino estudo do meio, tal qual demonstrado até aqui. Desta forma, procurou-se entre os projetos apresentados evidencias dessas relações.

\section{Os projetos apresentados na etapa distrital da IV CNIJMA, em 2013}

O processo das conferências iniciou-se no ano de 2009 , quando jovens manifestaram o interesse em também participar das Conferências de Meio Ambiente promovidas pela Organização das Nações Unidas (ONU) para debater questões referentes às mudanças climáticas globais.

Em 2013, já na IV edição das conferências, a delegação do Distrito Federal inscreveu um total de 39 projetos, dos quais avaliamos nove que tratavam do tema resíduos sólidos. Com o objetivo de identificar projetos de educação ambiental que contemplassem as potencialidades de um estudo do meio, elencamos as categorias analíticas: a) pensamento sistêmico; b) foco sobre a espacialidade local; c) equilíbrio entre conteúdos de aprendizagem. 
Na primeira, buscaram-se elementos que demonstrassem inter-relações entre os diferentes aspectos da realidade, com reflexões acerca de questões políticas, econômicas, ecológicas, culturais e sociais. Na segunda, procuraram-se referências ao contexto da comunidade na qual a escola está inserida e proposições que envolvessem diretamente elementos desse contexto. A última constituiu maior desafio, devido ao fato de os projetos raramente mencionarem os procedimentos pedagógicos utilizados em sua elaboração. Por isso, procuraram-se evidências, ao menos parciais, sobre o protagonismo discente, o que valoriza a atitude e o aprendizado procedimental.

Os temas abordados nos projetos podem ser divididos em lixo, água, plantios (reflorestamento e hortas) e escola sustentável. Os últimos, mais amplos, apresentaram propostas direcionadas ao desenvolvimento de várias ações integradas. Estas foram as que mais se aproximaram das propostas trazidas neste artigo. No entanto, julgou-se que a eficácia da avaliação de tais processos somente poderia ser comprovada com observação não participante, o que não foi possível no curto tempo da pesquisa.

Considerou-se que o tema lixo apresenta possibilidades mais explícitas de envolver os três critérios tomados na pesquisa. Isto se deve por este tema envolver significativamente um aspecto ecológico, dados a contaminação ambiental e o tempo de decomposição dos materiais, e outro social, devido aos brasileiros que exercem a atualmente reconhecida profissão de catadores de resíduos sólidos.

Os resíduos sólidos envolvem a todos. Dificilmente as escolas não enfrentam problemas relacionados em seu cotidiano. $O$ aprendizado adequado sobre formas próprias de proceder em relação aos resíduos podem envolver amplo debate: análise do padrão de consumo de determinado grupo social, com abertura do diálogo sobre temas ligados à política, à economia, às questões químicas e biológicas, à desigualdade social, entre outras.

Considerou-se os projetos relacionados aos resíduos sólidos a fim de identificar as características acima citadas. Os projetos pertinentes à nossa análise e seus objetivos podem ser vistos no quadro 1. 
QUADRO 1

PROJETOS APRESENTADOS NA IV CNIJMA COM TEMA RESÍDUOS SÓLIDOS

\begin{tabular}{|c|c|c|}
\hline & Projetos & Objetivos \\
\hline & Ecolixo & $\begin{array}{l}\text { Iniciar a transformação de toda a } \\
\text { comunidade escolar para que esta } \\
\text { mantenha como missão reciclar o lixo que } \\
\text { produz. }\end{array}$ \\
\hline 2) & $\begin{array}{l}\text { Lixo não polui, você é } \\
\text { que polui! }\end{array}$ & $\begin{array}{l}\text { Criar um Ponto de Entrega Voluntária } \\
(\mathrm{PEV}) \text { na escola para aumentar a } \\
\text { reciclagem dos materiais rejeitados pela } \\
\text { comunidade. }\end{array}$ \\
\hline 3) & $\begin{array}{l}\text { Água na escola } \\
\text { sustentável }\end{array}$ & $\begin{array}{l}\text { Retirar lixo de córrego próximo à escola e } \\
\text { limpar bueiros para evitar alagamento das } \\
\text { ruas do bairro. }\end{array}$ \\
\hline 4) & Escola bela & $\begin{array}{l}\text { Transformar o ambiente escolar em } \\
\text { um espaço agradável e favorável ao } \\
\text { aprendizado. }\end{array}$ \\
\hline & $\begin{array}{l}\text { Sem nome (CEF } 03 \\
\text { Braz.) }\end{array}$ & $\begin{array}{l}\text { Conscientizar os alunos sobre a } \\
\text { importância da reciclagem de materiais } \\
\text { reutilizáveis. }\end{array}$ \\
\hline 6) & Coisa imprestável? & $\begin{array}{l}\text { Conscientizar a comunidade escolar sobre } \\
\text { a necessidade de se produzir menos lixo, } \\
\text { reaproveitar e reciclar. }\end{array}$ \\
\hline 7) & Lixeira de pneu & Construir lixeiras de pneus. \\
\hline & $\begin{array}{l}\text { Lixo: nosso novo modo } \\
\text { de conviver }\end{array}$ & $\begin{array}{l}\text { Fazer oficinas para construção de } \\
\text { lixeiras de papelão para a separação dos } \\
\text { materiais. }\end{array}$ \\
\hline & Transformando o solo & $\begin{array}{l}\text { Deixar a escola mais limpa e agradável, } \\
\text { colocar novas lixeiras para a coleta } \\
\text { seletiva e fazer reciclagem de papel para } \\
\text { trabalhos de artes. }\end{array}$ \\
\hline
\end{tabular}

Fonte: Projetos apresentados na IV CNIJMA.

Elaboração própria. 
Algumas propostas demonstram contradições entre o texto discorrido como introdução e os objetivos gerais e específicos com os procedimentos para atingir os fins visados. Portanto, buscou-se desenvolver um olhar global sobre as propostas, considerando essas diferenças entre os textos e a proposta da prática em si.

Tendo como nosso primeiro critério o foco sobre a espacialidade local, identificou-se que três projetos apresentam elementos que demonstram relação. Os demais sequer citam o contexto da comunidade e suas especificidades. Dos três (projetos 2, 3 e 6), apenas um, o segundo, foi elaborado a partir da necessidade da comunidade local, que reconheceu os resíduos como um grande problema no bairro porque entupia o esgoto, que vazava com frequência. O terceiro apresentou características do bairro e, entre outras ações, propôs a limpeza dos bueiros entupidos para evitar o alagamento das ruas. O sexto limitou-se ao contexto da escola, apenas citando que um hábito comum na comunidade é jogar lixo no chão.

Em relação aos conteúdos de aprendizagem, houve dificuldade em identificar características que pudessem indicar seu desenvolvimento, visto que a maioria dos projetos não especificou a abordagem pedagógica. Procurou-se avaliar os procedimentos previstos nos projetos e julgou-se que os de número 4, 5, 8 e 9, por envolverem a realização de oficinas, em sua maioria para a construção de lixeiras com resíduos reutilizáveis, apresentam algum nível de aprendizado procedimental. Mas isso não se aproxima do aprendizado referente ao desenvolvimento de pesquisa, tal qual previsto em um estudo do meio. Todos visam, em algum nível, atingir a mudança de atitudes, mas nem sempre explicitam exatamente como esta se daria. Avaliar a eficácia do projeto neste sentido transcende os limites desta pesquisa.

Apenas os números 2 e 6 indicaram de forma mais evidente a possibilidade de haver maior equilíbrio nos conteúdos de aprendizagem. No entanto, no número 6 , que enfatiza a busca pela transformação de hábitos e atitudes, o procedimento para atingi-la parece questionável. Declara-se que os professores ficarão responsáveis por controlar a sujeira da sala e "os membros da coordenação e da direção darão as broncas mais profundas se algo não sair como o combinado". Além disso, prevê-se, enquanto metodologia, a realização de gincana, na qual a sala que se mantivesse mais limpa seria premiada. Questiona-se se desta forma os alunos deixariam de jogar lixo nas ruas, quando não serão premiados por não o fazer.

Já o projeto número 2 explica que foram apresentadas questões que envolviam os problemas ambientais da comunidade para as turmas e que "foram feitas atividades de problematização e também de proposição para que os estudantes pudessem refletir e ampliar seus conhecimentos relativos à temática". Este elemento é o que mais pode se aproximar da perspectiva aqui buscada.

Por último, nas questões referentes ao pensamento sistêmico, procurou-se identificar inter-relações entre diferentes elementos do espaço, como a relação das questões ambientais com as sociais. Apenas um dos projetos, o segundo, englobou 
questões ambientais e sociais de forma interligada.

A maioria das propostas foi direcionada às questões puramente relacionadas ao ambiente natural. Algumas frases como "contribuir para um planeta ecologicamente melhor" e "impactos que o excesso de lixo produzido causam na terra, no ar e nas águas de nosso ecossistema", identificadas no primeiro projeto, demonstram pouca vinculação aos aspectos sociais. Em suma, as propostas visam estabelecer um sistema de coleta seletiva na escola, mas não vinculam esta ação às questões cotidianas e muito menos às questões sociais.

No projeto de número 6 , chega-se a afirmar que "para muitas pessoas, lixo é fonte de renda"; contudo, não faz menção à destinação dos resíduos coletados na escola a partir do projeto. Este fato, inclusive, é identificado em praticamente todos. Evidenciam a necessidade de separar os resíduos na escola, mas não citam de que maneira fariam para que estes resíduos permanecessem separados ao sair da escola. Isto faz toda a diferença em um contexto no qual a coleta de resíduos pública não se dá de forma seletiva.

O projeto de número 2, que prevê a criação de um Ponto de Entrega Voluntária (PEV) na escola, é o único que aborda as questões sociais e demonstra relação entre os processos envolvidos na coleta seletiva do lixo. Entre as atividades do projeto, foi proposto contatar uma cooperativa de catadores para recolher os resíduos depositados na escola, já que, assim, acredita-se que "a escola está destinando os resíduos sólidos da comunidade de maneira adequada, tanto ambiental quanto socialmente". Além disso, afirma que tem como um dos objetivos específicos "a geração de renda e apoio à melhoria das condições de trabalho dos catadores de resíduos sólidos".

Em suma, o único projeto que apresentou elementos que pudessem indicar o atendimento aos três elementos aqui buscados, que são desejados pelas propostas teóricas e governamentais da educação ambiental, foi o segundo. Do restante, seis não apresentam nenhum dos elementos e dois os apresentam parcialmente, deixando dúvidas devido a contradições identificadas entre o texto e a proposta prática.

\section{Conclusões}

Após as reflexões acerca da temática, julga-se que o conhecimento geográfico em relação à espacialidade apresenta ferramenta teórica relevante para a educação ambiental que se proponha crítica. Entende-se que a metodologia de ensino estudo do meio constitui uma importante ferramenta pedagógica a ser utilizada na prática da educação ambiental formal, já que apresenta importantes elementos para atingir 
aos objetivos preconizados pela educação ambiental crítica.

Julga-se ser fundamental que os processos pedagógicos envolvam significativamente a capacidade de reflexão e criticidade, para que os sujeitos tenham instrumentais metodológicos e cognitivos para perseguir, selecionar e construir conhecimentos mais relevantes às suas vidas individuais e coletivas. Este processo deve, contudo, envolver as complexas cadeias que compõem a realidade. As escolas não podem limitar sua atuação ao desenvolvimento de conhecimentos lineares e segregados do todo que fazem parte. Os tempos atuais necessitam de sujeitos que compreendam profundamente as causas e consequências de suas ações e sejam orientados por valores e princípios que o façam interagir com a sociedade e com o meio de maneira mais ética e respeitosa.

É justamente nesse sentido que a educação ambiental mostra-se pertinente. No entanto, apesar do imenso avanço identificado no movimento ambientalista e nas consequentes propostas, tanto teóricas quanto nas propostas governamentais, a prática desta dentro de instituições escolares, salvo exceções, permanece restrita aos aspectos naturais. Esta limitação da prática pedagógica contribui para a manutenção do status quo e divulga uma educação ambiental ingênua e neutra.

Por isso se aponta que o foco na espacialidade, especialmente vinculada à prática interdisciplinar e investigativa do estudo do meio, potencializa o caráter transformador da educação ambiental. Essa associação apresenta suporte teórico e subsídios práticos para o desenvolvimento de uma pedagogia voltada à formação do pensamento autônomo e construção de valores éticos.

De um modo geral, os projetos avaliados abordam pouco a perspectiva da protagonização discente, do processo investigativo em si e a formação do pensamento autônomo, aspectos tão importantes para atingir uma gestão escolar democrática e, consequentemente, o fortalecimento da prática cidadã. Conclui-se, portanto, que há grande necessidade em se divulgar a metodologia estudo do meio e suas potencialidades nos processos que envolvem a formação de professores para atuar com a educação ambiental no âmbito da rede pública de ensino do Distrito Federal.

\section{Referências}

CARVALHO, Isabel. Educação ambiental: a formação do sujeito ecológico. São Paulo: Cortez, 2004.

FERNANDES, Maria Lídia Bueno. A prática educativa e o estudo do meio: o 
conceito de sustentabilidade em questão. São Paulo: Annablume, 2012.

FREIRE, Paulo. Educação como prática da liberdade. Rio de Janeiro: Paz e Terra, 1967.

. Medo e ousadia: o cotidiano do professor. São Paulo: Paz e Terra, 2011.

LAYRARGUES, Philippe Pomier. Educação ambiental com compromisso social: o desafio da superação das desigualdades. In: LOUREIRO, Carlos Frederico; LAYRARGUES, Philippe Pomier; CASTRO, Ronaldo Souza (Orgs.). Repensar a educação ambiental: um olhar crítico. São Paulo: Cortez, 2009.

LAYRARGUES, Philippe Pomier; LIMA, Gustavo Ferreira da Costa. Mapeando as macrotendências político-pedagógicas da educação ambiental contemporânea no Brasil. In: ENCONTRO "PESQUISA EM EDUCAÇÃO AMBIENTAL": A PESQUISA EM EDUCAÇÃO AMBIENTAL E A PÓS-GRADUAÇÃO NO BRASIL, 6., 2011, Ribeirão Preto. Anais... Ribeirão Preto: ICMBio, 2011. Disponível em: <http:// www.icmbio.gov.br/educacaoambiental/images/stories/biblioteca/educacao_ ambiental/Layrargues_e_Lima_-_Mapeando_as_macro-tend\%C3\%AAncias_da_ EA.pdf>. Acesso em: 14 jan. 2015.

LEFF, Enrique. Saber ambiental: sustentabilidade, racionalidade, complexidade e poder. Rio de Janeiro: Vozes, 2012.

LOPES, Claudivan Sanches; PONTUSCHKA, Nídia Nacib. Estudo do meio: teoria e prática. Geografia, Londrina, v. 18, n. 2, p. 173-191, 2009. Disponível em: <http:// www.uel.br/revistas/uel/index.php/geografia/>. Acesso em: 15 set. 2014.

LOUREIRO, Carlos Frederico. Problematizando conceitos: contribuição à práxis em educação ambiental. In: LOUREIRO, Carlos Frederico; LAYRARGUES, Philippe Pomier; CASTRO, Ronaldo Souza (Orgs.) Pensamento complexo, dialética e educação ambiental. São Paulo: Cortez, 2006.

SANTOS, Milton. Espaço e Método. São Paulo: Edusp, 2008a.

. Por uma outra globalização: do pensamento único à consciência universal. Rio de Janeiro: Record, 2008b.

2012.

A natureza do espaço: técnica e tempo, razão e emoção. São Paulo: Edusp,

ZABALA, Antoni. Os enfoques didáticos. In: COLL, Cesar et al. (Orgs.). O construtivismo na sala de aula. São Paulo: Ática, 2009. 
Recebido em junho de 2015.

Aprovado em outubro de 2015.

Luna Letícia de Mattos Lambert é mestre em Educação Ambiental e Ensino de Geografia pela Universidade de Brasília (UnB). Atua como professora da rede pública de ensino do Distrito Federal, em nível de ensino fundamental. E-mail: <anullambert@gmail.com>

Maria Lídia Bueno Fernandes é doutora em Geografia pela Universidade de São Paulo (USP) e professora da Universidade de Brasília (UnB), atuando na graduação e no Programa de Pós-Graduação em Educação da Faculdade de Educação (FE) da UnB. Está vinculada ao Núcleo de Estudos em Cultura, Oralidade, Imagem e Memória do Centro de Estudos Avançados Multidisciplinares (CEAM) da UnB.

E-mail: <lidia_f@uol.com.br>. 